\title{
Lost in Translation: Exploring the Ethical Consumer Intention-Behavior Gap
}

\author{
Michal J Carrington, La Trobe University \\ Benjamin A Neville, University of Melbourne \\ Gregory J Whitwell, University of New South Wales
}

The authors thank Liliana Bove, University of Melbourne, and Graham Sewell, University of Melbourne, for reading and commenting on an early version of this article. The authors also thank Journal of Business Research Associate Editor Drew Martin and the anonymous reviewers for their insightful comments and suggestions. Send correspondence to Michal J. Carrington, La Trobe Business School, La Trobe University, Melbourne, Victoria, Australia, telephone: +61-3-94792178/+61-3-9479-5971. (M.Carrington@latrobe.edu.au). 


\begin{abstract}
Ethical consumerism is a burgeoning movement, yet ethically-minded consumers rarely purchase ethically. Understanding obstacles to ethical consumption is limited. This study explores the underlying mechanics of the ethical purchase intention-behavior gap in the context of consumers' daily lives. The study employs multiple qualitative methods across multiple sites, explores the intention-behavior gap in observed modes of shopping behavior, and uses an interpretive approach. The analysis reveals four interrelated factors affecting the ethical intention-behavior gap: (1) prioritization of ethical concerns; (2) formation of plans/habits; (3) willingness to commit and sacrifice; and (4) modes of shopping behavior. Awareness of these four factors provides both strategic and tactical implications for marketing managers seeking to reach the elusive ethical consumer. Understanding and enhancing ethical consumption - closing the gap - has positive outcomes for the future sustainability of economies, societies and environments.
\end{abstract}

Keywords: Ethical consumerism, intention-behavior gap, ethnography, prioritization, habits, implementation intentions. 


\section{Lost in Translation: Exploring the Ethical Consumer Intention-Behavior}

\section{Gap}

\section{INTRODUCTION}

Ethical consumerism is a burgeoning social movement. Mainstream consumers increasingly express concerns about the ethicality and impact of their consumption choices upon the environment, animals and/or society (De Pelsmacker, Driesen, \& Rayp, 2005; Shaw \& Shui, 2002). For example, recent UK market data, suggests the ethical food and drink market represents eight percent of the total food and drink market (Co-operative Bank, 2010). Despite embracing the values of ethical consumerism, most consumers rarely support their beliefs at the check-out counter (Auger \& Devinney, 2007; Belk, Devinney, \& Eckhardt, 2005; Szmigin, Carrigan, \& McEachern, 2009). For example, 89 percent of UK consumers report they have ethical issues of concern (Lazzarini \& de Mello, 2001), however, a 2005 study reports that only 30 percent of UK consumers convert these concerns into ethical purchase intentions, and only three percent actually purchase ethical products (Futerra, 2005).

Researchers refer to the misalignment of ethical intentions into actual behavior alternately as the attitude-behavior, intention-behavior or words-deeds gap (Carrigan \& Attalla, 2001; Elliot \& Jankel-Elliot, 2003). The ethical consumerism, psychology, social psychology and consumer behavior domains variously document, but they do not explain the intention-behavior gap (Bagozzi, 2000; Sheeran, Trafimow, \& Armitage, 2003; Szmigin et al., 2009). A growing body of research attempts to understand ethical purchase decisionmaking (e.g., Shaw and colleagues, 1999, 2002, 2006, 2007; De Pelsmacker et al., 2005; Vermeir and Verbeke, 2008), but these studies primarily focus on the formation of ethical purchase intentions. The translation from intentions to actual buying behavior remains poorly 
understood (Auger, Burke, Devinney, \& Louviere, 2003; Belk et al., 2005; De Pelsmacker et al., 2005; Szmigin et al., 2009).

This study sheds light on the intention-behavior (I-B) gap in an ethical consumption (EC) context. The study addresses Fisk's (1998, p.661) reflection that: “a sustainable society is a great idea, but how can the world's 5.7 billion people be redirected to adopt sustainable society practices? No one knows”. Marketers express similar frustrations and acknowledge that marketing strategies to reduce the EC I-B gap provide marginal impact at best (Crane \& Matten, 2004; Polonsky, 1995). Understanding and bridging the inconsistencies between what ethically-minded consumers intend to purchase and actually consume hold significant benefits for academia, industry, and society at large. To provide insights into the mechanics of why ethically-minded consumers often fail to enact their ethical purchasing/consuming intentions, the study draws upon the methodological framework presented by Edmondson and McManus (2007). The study combines a qualitative research methodology with grounded analysis (Glasser \& Strauss, 1967) to explore the EC I-B gap.

\section{BACKGROUND}

This section has two purposes: (1) to provide a critical examination of the literature on the EC I-B gap; and (2) to establish qualitative research as an appropriate method for understanding this gap.

\subsection{Ethical Consumer Decision Making}

Ethical consumers 'have political, religious, spiritual, environmental, social or other motives for choosing one product over another' (Harrison, Newholm, \& Shaw, 2005), and they express concern about their consumption choices' impact. What is ethical, however, 
encapsulates different expressions, concerns, and issues for each individual. Ethical consumption relates to the ethics of consumption, which concerns the ethics of capitalist market systems and the reduction of consumption overall (Barnett, Cafaro, \& Newholm, 2005). Ethical consumption also serves as a medium for ethical/moral action based on subjective moral judgments applied to individual products/brands across the production, consumption and disposition cycle (Brunk, 2010).

Ethical consumerism researchers attempting to understand the purchase decisionmaking of ethically-minded consumers tend to apply cognitive modeling approaches (Fukukawa, 2003), most commonly the Theory of Planned Behavior (TPB) (Ajzen, 1991; Chatzidakis, Hibbert, \& Smith, 2007; De Pelsmacker \& Janssens, 2007; Vermeir \& Verbeke, 2008). These researchers focus on integrating factors into the TPB framework that influence the formation of ethical purchasing intentions, such as internal ethics (Shaw \& Clarke, 1999; Shaw \& Shui, 2002), information quality and quantity (De Pelsmacker \& Janssens, 2007), and personal values (Vermeir \& Verbeke, 2008). These studies tend to focus on forming stated intentions, and assume that ethical purchase intentions directly determine actual buying behavior (Fukukawa, 2003). This assumption ignores empirical studies in the broader contexts of consumer behavior and social psychology suggesting that purchase intentions do not usually translate into actual buying behavior (Ajzen, Brown, \& Carvajal, 2004; Bagozzi, 2000; Morwitz, Johnson, \& Schmittlein, 1993; Young, DeSarbo, \& Morwitz, 1998).

\subsection{The Ethical Consumption Intention-Behavior Gap}

A few researchers move beyond cognitive intention formation to gain insight into the translation between EC intentions and actual behavior. For example, Carrigan and Attalla (2001) reveal that social desirability bias plays a significant role in their respondents' ethical I-B gap. Auger and Devinney (2007) extend this finding by positing that social desirability 
bias inherent in the self-reported surveys favored by researchers in the ethical consumerism field inflates espoused ethical purchase intentions.

Most recent studies tend to assume some ethical intentions are authentic; however, internal and external factors affect actual purchase decisions. These conceptual and exploratory insights extend the overall understanding of the EC I-B gap, yet the research only provides a partial, emergent understanding of this phenomenon (Szmigin et al., 2009). For example, Carrington, Neville and Whitwell (2010) conceptually argue that the extent to which consumers translate their ethical intentions into buying behavior depends upon their prior planning (e.g., implementation intentions; see Gollwitzer 1999), their control over the buying experience (e.g., actual behavioral control; see Ajzen and Madden 1986), and aspects of the buying environment (e.g., situational context; see Belk 1975). This conceptual model remains unexplored empirically.

Some exploratory research indicates that the EC I-B gap's perpetuation by consumer's employment of cognitive strategies to minimize remorse and to justify contradicting their ethical intentions (e.g., Szmigin et al., 2009; Chatzidakis et al., 2007). In this vein, Szmigin et al. (2009) find that a lack of cognitive dissonance facilitates the EC I-B gap. The ability of ethical consumers to readily rationalize or neutralize their 'unethical' purchasing behavior partially explains the absence of cognitive dissonance (Szmigin et.al, 2009). Chatzidakis et al. (2007) draw upon neutralization theory to propose that the ability to rationalize unethical purchasing behavior as being acceptable, though not ethical, facilitates the observed EC I-B gap.

\subsection{Methodological limitations}

The ethical consumerism literature favours quantitative methods, in particular selfreported surveys (Auger \& Devinney, 2007). The decision-making process and translation 
between purchase intentions and shopping practices is highly complex and the established survey-based methods for observing ethical consumption fail to capture this complexity (De Pelsmacker et al., 2005; Freestone \& McGoldrick, 2008; Shaw, Newholm, \& Dickinson, 2006; Szmigin et al., 2009). An ethical research context amplifies social desirability bias (Carrigan \& Attalla, 2001), further limiting the accuracy of the extant survey-based research (Auger \& Devinney, 2007; Belk et al., 2005). In addition, traditional quantitative methods studies on ethical behavior are more suitable to verify theory (Deshpande, 1983). This nascent field of EC I-B research, however, requires a theory construction approach.

In summary, the literature on the EC I-B gap is sparse and provides limited understanding of the gap. Furthermore, previous survey-based methodological approaches fail to grasp ethical consumption's complexity or to develop compelling theory to explain the phenomena. In light of these theoretical and methodological shortcomings, and in line with other recent research on ethical and sustainable consumption, this study uses a qualitative approach (e.g., Belk et al. 2005, Szmigin et al. 2009), which is especially effective for constructing theory (Corbin \& Strauss, 2008; Edmondson \& McManus, 2007). Employing an ethnographic research strategy helps to gain an in-depth understanding of this complex phenomenon (Goulding, 2005). Observing daily practices and complicated decision-making challenges at close range provides a better understanding of why ethically-minded consumers rarely place ethical products in their shopping baskets.

\section{RESEARCH METHODS}

The ethical concerns and purchasing practices of 13 informants were explored over a nine-month immersive study. The informant profile and study sample were chosen purposely using a maximum variation sampling rationale (Miles \& Huberman, 1994), starting with 
extreme cases in the initial analytic cycle and then moving along the spectrum of ethical consumption experiences in subsequent recruitment cycles to broaden/strengthen the research findings and obtain theoretical saturation (Corbin \& Strauss, 2008). To assist with the maximum variation sampling strategy, potential informants were asked in an initial screening interview to self-classify in terms of how successful they perceived themselves to be as ethical consumers. The potential participants responded with self-classifications, using invivo terms (Corbin \& Strauss, 2008) such as 'hard-core', 'moderate', 'just aware' or 'not aware' that were comparable to 'high', 'moderate', and 'low' categorization. Care was also taken to maximize the diversity of composition of the participants across educational backgrounds, age, gender, life stage, employment, household composition and marital status to ensure that a wide range of experiences and perspectives were integrated into the study (Cherrier, 2005). Further, informants held a diverse range of ethical consumerism concerns that spanned the entire life cycle of products and services (e.g., production, supply, consumption and waste) and the impact of consumption upon the environment, animals, economies and society. They individually expressed these concerns through eclectic selections of issues, including: waste, packaging minimization, second-hand shopping (for waste and sweatshop labor), vegetarianism, veganism, recycling and recycled products, sustainability (economic, environmental and social), fair trade, organic production (for soil health, GM-free and environmental concerns of mono-agricultures), market monopolization, carbon footprint, sweatshop/child labor, building local skills and communities, animal rights and welfare, and the ethics of the organizations that they support with their spending.

The study comprises two sequential data sets. The first data set involved four informants over five months, recruited through the email newsletter of an ethical consumerism group. Three of the four informants identified themselves as being "hard-core" or "die-hard" ethical consumers during the screening interview, yet all respondents 
acknowledged that they are not always successful in implementing their ethical intentions at the cash register. The second data set extended over four months and included nine informants. These informants were recruited using a viral e-mail technique, starting with an ethically-minded consumer and snowballing from this original source. This e-mail snowballed through a number of government departments and private sector firms, and then further through social networks. Initially, six informants were selected who self-identified themselves as being "moderate" or "just aware" ethical consumers. As the research evolved, an additional three informants who saw themselves respectively as "hard-core", "moderate", and "just aware" ethical consumers, were recruited strategically from the participant pool to confirm the saturated concepts across a spectrum of self-identified ethical consumers (Corbin \& Strauss, 2008).

\section{Table 1 here.}

All informants participated in semi-structured depth interviews in their homes or at a similar location where they felt that they could speak freely. The interviews were structured around a string of grand-tour questions (Spradley, 1979). Interviews with the hard-core informants lasted two to three hours. In contrast, the initial in-depth interviews with the moderate and just aware informants were one to two hours in duration as they had fewer ethical concerns and their depth of awareness regarding their concerns and consumption behavior was lower. Each informant then voluntarily participated in a variety of methods, including accompanied shopping trips, written and photographic shopping diaries, and projective interviews. The principal researcher also was invited by the informants as a participant-observer to events such as film nights where ethical consumption documentaries were shown, ethical sewing workshops where second-hand garments were cut-up and the fabric remade into new items, community cooperative workshops, and informal social events. 
Taking a multi-method approach enabled observation of both stated intentions and actual behavior to address the study aims.

The data were analyzed using an interpretive, grounded approach in line with the study aims and the emergent state of the literature (Edmondson \& McManus, 2007; Glasser \& Strauss, 1967). The data (text, audio and visual) were uploaded into Nvivo (a software package) immediately after collection to enable a continuing interplay (Goulding, 1999) between the data collection and data analysis. This interplay allowed new data to be analyzed in the context of previous data analysis to evolve and refine emerging concepts (Hammersley \& Atkinson, 2008). Observations arising from the first data set were open-coded inductively (Spiggle, 1994) at the micro-level. The micro-analysis (Corbin \& Strauss, 2008) produced 131 open-codes, and abstraction methods identified higher-order theoretical concepts and relationships (Spiggle, 1994). Analysis then moved into a constant comparative technique for the second data set to further develop the concepts and their relationships until saturation was achieved (Corbin \& Strauss, 2008; Spiggle, 1994). At this point, a wide range of literature was sampled to sensitize and frame the saturated theoretical constructs (Goulding, 1999).

Several strategies were employed to ensure trustworthiness of the data and analytic interpretation. Table 2 is categorized by the informant profiles (HC, Mod, JA) and outlines the multiple research methods that concurrently tested and refined emerging interpretations. First, a three-pronged approach to triangulation across research methods, sources and sites was employed (Arnould \& Wallendorf, 1994; Hammersley \& Atkinson, 2008; Lincoln \& Guba, 1985; Miles \& Huberman, 1994; Wallendorf \& Belk, 1989), as well as a multi-sited approach (Marcus, 1995). The latter involved observing informants at home, at work, and in social and shopping situations.

Table 2 here. 
Second, prolonged engagement with individuals/households and persistence in the field brought credibility and integrity to the data (Lincoln \& Guba, 1985; Wallendorf \& Belk, 1989). Table 3 illustrates the scope and volume of data collected. Several data recording methods were used that included field notes, audio and video recordings, hand written participants diaries, and photographs. Third, the combination of the sampling strategy with a constant comparative analysis technique (Corbin \& Strauss, 2008), akin to negative case analysis (Lincoln \& Guba, 1985; Miles \& Huberman, 1994), enabled testing and expansion of the dimensions and relationships between the emerging interpretations. Finally, selective member checks were employed and regular research team de-briefs occurred throughout the research cycles to discuss the emerging etic interpretations (Lincoln \& Guba, 1985; Wallendorf \& Belk, 1989). Feedback from colleagues not involved in the study was also sought and received (Lincoln \& Guba, 1985).

Table 3 here.

\section{FINDINGS}

The study informants endeavored to align their ethical concerns and purchasing/ consumption on a daily basis. The analysis reveals a motivational hierarchy that guides the selection and enactment of ethical consumption concerns over three interconnected levels; ethical consumption core values at the base, then the integration of ethical consumption values into consumer lifestyles, and finally consumption enactments through different modes of shopping. Shopping modes refer to the "varying patterns of information search, alternative evaluation, and product selection” (Brown, Pope, \& Voges, 2003, p. 1668).

Figure 1 here. 
This core motivational framework and the resulting enactment of ethical values in consumption decisions, is contingent upon four factors influencing the mis/alignment of ethical intentions and actual shopping behavior: (1) prioritization of ethical concerns; (2) formation of plans and habits; (3) willingness to commit and sacrifice; and (4) modes of shopping behavior. This motivational framework was observed across all informant classifications, Hard Core (HC), Moderate (Mod) and Just Aware (JA).

The remainder of this paper details the findings, analysis, and interpretations of the data, and presents conceptual relationships between four emergent factors found to be at the crux of the ethical intention-behavior gap. The discussion section highlights the implications of these findings and presents paths for future research.

\subsection{Prioritizing ethical concerns: primary or secondary}

The process of embedding ethical issues into daily life is gradual and difficult. This process involves becoming informed about the ethical issue, negotiating internal and external objectives, and persisting until the new behavior becomes habitual. Informants focus on embedding only one or two ethical concerns into their shopping and consuming habits at a time as they juggle busy lives and complex layers of both ethical and non-ethical concerns. This focus requires prioritization to avoid being paralyzed by the enormity of effort required by their full set of ethical concerns, and because of the limits to what they are "prepared to do or could physically do" (Brigit, HC).

Informants prioritize their overall set of ethical issues into two groups, issues of primary importance and issues of secondary importance (peripheral to their conscious ethical consumption). Primary ethical issues most strongly resonate with informants' personal ethical values. They are a "high priority to how I live...not an optional extra to my life" (Rachel, Mod) and "guide a lot of decision making" (Beth, Mod). For example, Rachel primarily 
focuses on greenhouse emissions, while Brigit's primary concern is the creation and disposal of waste. Focusing on primary ethical issues mobilizes informants and enables them to concentrate on making changes step-by-step. Informants are either in the process of integrating primary issues into their shopping/ consumption habits, or they have already embedded these issues into their routine choices.

In contrast, ethical issues of secondary importance are considered to be important but "further down on the ethical scale, where they might be more sporadic kinds of smaller activities" (Brigit, HC). Accordingly, secondary ethical concerns often are forgotten, rarely integrated into shopping plans, and traded off with other salient considerations such as cost, convenience, and other ethical issues when placing items in shopping baskets.

Informants possess their own complex combination of primary and secondary ethical concerns. This prioritization significantly impacts the contents of shopping baskets and consumption routines. Primary ethical issues constantly affect daily choices, becoming habitually aligned with purchase/consumption behavior. Secondary ethical concerns are not actively planned or habitually developed, and they are unlikely to be consistently followed through to purchasing/consumption behavior. In this unplanned situation, secondary ethical concerns are often compromised and contribute to the intentions-behavior gap.

Informants manage to thread several primary concerns into their day-to-day decisions. Table 4 outlines these key distinguishing features between the informant profiles (HC, Mod and JA). These distinguishing categories correspond to typologies proposed by Elgin and Mitchell (1977) to categorize voluntary simplifiers, and they are included to further explain the EC I-B gap in light of emergent concepts.

Table 4 here

\subsection{Plans and habits}


Forming plans before embarking on a shopping trip is a highly effective tool used by informants to ensure that their ethical intentions translate into their shopping basket. These plans play an essential facilitation role between the desire to consume ethically and actual consumption routines changes. Informants' plans range from simple written or remembered shopping lists to imagined/rehearsed complex multi-step processes. The existence of a plan helps to avoid distraction and spontaneous purchases when in the shopping environment. Preplanning also assists respondents to remember, break old habits, and form new habits that make ethical shopping easier. For example, Peter (Mod) prefers to "do all the research first before going out", so that when he arrives in the store he already knows "exactly what I want and what I don't want", reducing the pressure of making ethical choices and assisting him to avoid buying products wastefully. Conflicting internal and external priorities noticeably are absent from the act of choosing the ethical product for planned/habitual purchases, as the negotiations occurred during the planning process.

Many informants readily categorize themselves as highly planned in the shopping and consumption context: "we're very much planners...when we buy anything it's highly planned" (Claire, Mod). Making these plans is a conscious activity that requires commitment, effort and awareness. Specific and realistic plans are easier to enact, and to develop specific plans informants need to have practical knowledge of what/where/how they are going to purchase ethically-aligned products. Beth (Mod), who is primarily concerned with organic production and soil health, illustrates the effort required to do the practical research and set up her plans.

"When I first moved to this area I was looking up organic food shops, trying to find what was around and how close each one was to home...and I looked up the address... and worked out how I would get to each shop in terms of on the weekend or after work and tried to incorporate that into my habits". 
Plans are integral to forming ethical consumption habits. Practical knowledge is developed, the specific plan is formed and enacted, and over repeated enactments the actual planning - as well as the shopping behavior - gradually becomes habitual. Making plans and developing ethical consumption habits enables informants to reduce compromises against their ethical consumption ideals. In contrast, the absence of an ethical plan/habit often leads to compromises, trade-offs, frustration, and misaligned shopping habits. The absence of a rehearsed implementation plan triggers existing non-ethical habits to influence shopping behavior supplanting ethical attitudes and intentions (Verplanken, 2006).

Habitual ethical shopping behaviors of informants often seem effortless, such as taking used bags for shopping, going to the market to buy fair trade coffee, and rifling through second hand stores to buy kitchen utensils. The infrastructure underlying these habits, however, is often complex, negotiated and difficult to construct. Desiring to consume ethically, informants often seek consumption choices outside the mainstream market offering. Many ethical choices and aligned behavioral changes are not as simple as just choosing to buy something different in the same store; alternatives must be found, such as finding new stores and negotiating transport options. Breaking old habits and forming new ethical shopping habits requires an effort beyond ethical product selection. Entire behavioral patterns, processes, and dimensions must be stripped back, re-layered, built-up and made habitual to enable consistent ethical choice at the cash register. Processes and planning tools, such as taking containers to the market to avoid disposable packaging, are essential for informants to make ethical choices routine and part of daily life. Informants build these complex webs of underlying and habitual processes to make ethical choices easy choices and to reduce their own EC gap.

\subsection{Commitment and Sacrifice}


In certain situations and product categories, however, informants are unable to make plans or to develop ethical shopping habits because they are unwilling to commit to the ethically-aligned choice. Resistance to commitment and related unwillingness to sacrifice is an underlying mechanism to the EC I-B gap.

The market often does not provide acceptable and/or accessible options to enable informants to align their purchasing/consumption with their primary ethical concerns. This situation creates commitment and sacrifice issues not experienced in other (non-ethical consumption) contexts. The factors underlying commitment avoidance are twofold: first, in previous experiences the ethical choice has not been acceptable; and second, informants find that they are trading-off between multiple primary concerns and are unwilling to permanently commit to purchasing choices aligned with one ethical concern at the expense of the other. A sense of dissatisfaction with the available ethical choices leads to an unwillingness to commit in both of these situations, where informants have ethical intentions but they are unwilling to develop specific shopping plans/habits.

In contrast, Beth (Mod) displays willingness to commit a satisfactory ethical product to habit: "within the stock range of the particular shop that we go to we've tried out a few products and we've found one that we like and we stick with that...[it] is a satisfactory product for us and we buy it again and again". When informants commit to long-term ethical consumption routines, this decision often involves sacrificing purchasing power (higher cost), convenience, social acceptance and/or perceived quality. This sacrifice often has to be negotiated by the self and with others, posing both functional and mindset barriers to be overcome. To accept this sacrifice requires a high-level of commitment generally reserved for primary ethical issues only, for which the informant's sense of identity and ethical framework is at stake. High commitment levels exist for primary ethical concerns, and sacrifices routinely are made for ethically aligned products that exceed the concessions made for other 
products. Consuming in contradiction to primary ethical concerns for which a commitment had been made, often results in significant regret, as illustrated by Sally (HC):

"A few months ago, I purchased an iPhone, which I'd looked forward to.

About six weeks after I purchased it, I read about the manufacturer of iPhones. I have not used it since without a heavy heart. I've gotten [this] feeling of terrible regret”.

Sacrifice and long-term commitment reduce the EC I-B gap. These acts are not similarly evidenced for secondary ethical concerns where the gap is more pronounced.

\subsection{Behavioral Modes}

Ethical issue prioritization influences ethical purchasing plans/habits, and willingness to commit/sacrifice manifest in three observed shopping modes. Observing a single informant on a single shopping trip provides evidence each mode occurs as ethically aligned/misaligned products enter the shopping baskets.

\subsubsection{Pre-meditated and rapid shopping behavior}

Some respondent shopping behavior is pre-meditated and rapid. Brigit (HC) demonstrates this behavioral mode when she extends her arm, picks up and places an organic tofu product into her shopping basket with barely a glance at the shelf, while still walking and talking. When arriving at a product category in the store (e.g., soy milk), armed with a specified plan of intended purchases or an established purchasing habit, informants tend to stick with these plans/habits, rapidly and effortlessly choosing an ethically-aligned product. This shopping behavior occurs in the absence of conflict - either internal within the informant or external with others involved in the decision - as conflicting priorities have been negotiated and resolved. This behavioral mode is rapid, effortless and intentional because the 
purchase decision was made prior to entering the shopping environment and the plan or habit is enacted automatically at the shelf. Products linked to primary ethical issues generally are purchased in this intentional mode of shopping behavior. Shopping in this mode reduces the EC I-B gap.

\subsubsection{Effortful decision-making at the point of purchase}

Decision-making is effortful, frustrating and time consuming in this shopping mode, because informants have not made plans, their plans lack specificity, or they are yet to establish ethical shopping habits in a particular product category. With intentions unraveling in the face of many choices at the shelf, informants must go through the whole decisionmaking process in the store, juggling and re-evaluating all of their salient concerns (ethical and non-ethical), often resorting to reading labels and searching for information to aid decision-making. Helen (HC) articulates this process of effortful decision making at the shelf: "You just get so stuck in the quagmire of the different options, what's best, what's not, and how to decide". Ethical intentions often are lost in the midst of this extended effort.

\subsubsection{Spontaneous shopping}

Helen's (HC) "little spending bonanza" encapsulates this shopping behavior mode. She describes buying "a pair of sunglasses for no good reason at all”. Though spontaneous shopping behavior often results in ethically-misaligned purchase decisions, this result is not always the case. For example, while Claire (Mod) found herself impulsively buying sweatshop manufactured clothing "because it was cheap", Brigit (HC) tells of spontaneously buying a copy of The Big Issue magazine when she saw a homeless street vendor by chance. Spontaneous shopping is unplanned, sporadic, influenced by the situational environment, and often associates with secondary ethical concerns and I-B gaps. 


\section{DISCUSSION AND CONCLUSIONS}

\subsection{Prioritization Underpins the I-B Gap}

The study reveals that the translation of intentions into behavior is contingent upon the prioritization of ethical concerns, and that not all concerns are of equal salience. Ethical issue prioritization is integral to the observed mechanisms of plans and habits, and commitment and sacrifice. This core process significantly impacts which ethical concerns translate into purchasing/consumption, and which fall into the I-B gap. The prioritization process's complete influence is apparent when integrated with the related concepts of plans, habits, sacrifice, commitment, and behavioral modes emergent in the study.

\subsection{Implications for plans and habits theory}

Simple acts of making plans and developing habits create a powerful platform to successfully bridge the EC I-B gap in an ongoing, sustainable way. This planning conceptually aligns with the notions of implementation intentions (Gollwitzer, 1999; Gollwitzer \& Sheeran, 2006), and implementation plans (Dholakia, Bagozzi, \& Gopinath, 2007). This finding provides evidence for Carrington et al.'s (2010) notion of implementation intentions as a mediator of the relationship between EC intentions and behavior, thus contributes to the ethical consumption literature.

In addition, the study extends the conceptions of these plan constructs to view the act of planning as a multi-dimensional, multi-layered concept. Planning to facilitate behavioral change requires practical knowledge, the de-construction of existing and habitual consumption patterns, and the construction of new habitual routines. This conscious effort is 
relevant particularly in contexts where consumers must move outside the mainstream market to change habits and enact desired behaviors. As a multi-dimensional construct that creates a web of enabling structures, planning includes elements such as transport, shopping location, time dimensions, links to other routines such as work activities, as well as the product. The effort required to develop these multi-dimensional plans renders the individual capable of building specific plans for primary ethical issues only.

The study also extends the notions of implementation intentions/plans with the integration of habits into an overarching concept. Subsuming habits within the broader concept aligns with a renewed interest in the habits construct within the social psychology literature (e.g., Webb, Sheeran and Luszczyuska, 2009; Papies, Aarts and de Vries, 2009). Whether founded upon implementation plans or shopping habits, the resulting behavior for informants is identical - rapid and pre-meditated enactments of planned/habitual behavior in a state of automaticity. This finding is consistent with Holland et al.'s (2006) conceptual merging of plans and habits. Plan repetition and reinforcement leads to the breaking of old habits and forming of new habits (Webb et al., 2009), gradually reducing the EC I-B gap.

\subsection{Understanding the salience of ethical concerns and theoretical implications}

The conscious consumption participants in Szmigin et al.'s (2009) study display flexibility in ethical and non-ethical purchase choices "dependent on their own mood and factors such as price, quality, convenience, taste and the desires of others close to them" (p. 228). This flexibility results in participants displaying minimal cognitive dissonance with their EC I-B gaps. In contrast, the present study's informants display and articulate significant cognitive dissonance when consuming in contradiction to their primary ethical concerns, but displayed flexibility for their secondary ethical concerns. 
To grasp the discord felt by informants when consuming in contradiction with primary ethical concerns and their willingness to sacrifice for these primary causes, requires an understanding of how primary ethical concerns differ from other salient concerns such as price, social acceptance and other ethical issues. Informants experience a deep sense of discord with misaligned choices and they are prepared to make sacrifices because shopping/consuming in alignment with their ethical consumption values provides a sense of "connecting with who you are and where you come from, it feels like you are living your truth" (Sally, HC). Ethical choices alignment with primary ethical concerns is highly salient because they align with one's sense of self and deeply rooted personal values (Tybout \& Yalch, 1980; Vinson, Scott, \& Lamont, 1977). Awareness of an ethical issue that strongly resonates with this ethical value framework (e.g., through word-of-mouth or mainstream media) sparks this previously latent ethical value system to life in the consumption context. Once switched-on, deep commitment to this value-driven consumption results in an ideal identity shift (Kleine \& Kleine, 2000), and the subsequent prioritization of this ethical personal value to guide everyday consumption behavior (Tybout \& Yalch, 1980). Insight into personal values and the sense of discord when these values are violated provides an understanding of what sets the primary ethical concerns of ethically-minded consumers apart from other salient factors.

\subsection{Integrating the Emergent Concepts and Conceptualizing Relationships}

The analysis reveals four factors that influence the ethical I-B gap: (1) prioritization of ethical concerns into primary or secondary; (2) formation of plans or habits; (3) willingness to commit and sacrifice; and (4) shopping behavior modes. These factors interconnect across the three conceptual levels illustrated in Figure 1, and work as an integrated whole to influence purchasing/consumption behavior. 
The three levels and relationships between the four factors are interconnected as follows. It is a characteristic of primary ethical concerns that consumers are more likely to construct plans and make commitments/sacrifices. Gradually, these actions facilitate the development of ethically-aligned habits. Habitual behavior becomes automatic and effortless, resulting in pre-meditated and rapid shopping behaviors and consistent ethically aligned consumption. Similarly, it is in the very nature of secondary ethical issues that consumers are less likely to research and develop purchase plans for them. Specific commitments are rarely made resulting in unplanned effortful shopping behavior, erratic ethically aligned consuming practices and the EC I-B gap. These relationships and their cumulative effect upon the EC I-B gap provide a theoretical contribution to the ethical consumerism literature (see Figure 2). This figure also draws attention to the complexity involved in EC decision making, with shaded lines illustrating that secondary ethical concerns do sometimes influence the shopping basket's contents, while primary ethical issues may at times be forgotten or put aside. Brigit illustrates this complexity when spontaneously purchasing a 'Big Issue' magazine from a homeless street vendor, making an impulsive and unplanned shopping decision consistent with one of her secondary ethical concerns.

Figure 2 here

The analysis suggests that the process of prioritization, commitment/sacrifice, plans/habits, and the shopping mode influence the translation between EC intentions and actual buying/consuming behavior. The analysis also highlights a number of obstacles to ethical consumption, all of which could be the subject of future research. Obstacles include alternative personal values, extant habits, inability to form plans, unwillingness to make a commitment/sacrifice, lack of available information and an unwillingness to conduct effortful searches for information, and the distraction of the situational environment in effortful and spontaneous shopping modes. 


\subsection{Limitations and Future Research}

The study takes a qualitative approach with the aim of theoretical contribution. One strength of this research strategy lies in the element of realism, yet therein also lays a prominent methodological limitation as the quest for authenticity comes at the cost of generalizability (McGrath, 1994). Concepts emergent in this study may benefit from taking a hybrid/mixed approach to further research, employing complimentary quantitative methods to further explore and generalize their properties and dimensions (Carrington et al., 2010).

Employing quantitative methods in further study would assist the exploration of mediating and moderating properties of the four emergent factors upon the relationship between intentions and behavior. In addition, similar immersive studies could elicit further understanding of the meanings associated with this complex and important phenomenon in the lives of ethically-minded consumers and their communities. 


\section{REFERENCES}

Ajzen, I. (1991). The Theory of Planned Behavior. Organizational Behavior and Human Decision Processes, 50, 179-211.

Ajzen, I., Brown, T. C., \& Carvajal, F. (2004). Explaining the Discrepancy Between Intentions and Actions: The case of Hypothetical Bias in Contingent Valuation. Society for Personality and Social Psychology, 30(9), 1108-1121.

Ajzen, I., \& Madden, T. J. (1986). Prediction of goal-directed behavior: Attitudes, intentions and perceived behavioral control. Journal of Experimental Social Psychology, 22, 453-474.

Arnould, E., \& Wallendorf, M. (1994). Market-Oriented Ethnography: Interpretation Building and Marketing Strategy Formulation. Journal of Marketing Research, 31, 484-504.

Auger, P., Burke, P., Devinney, T. M., \& Louviere, J. J. (2003). What will Consumers Pay for Social Product Features? Journal of Business Ethics, 42, 281-304.

Auger, P., \& Devinney, T. M. (2007). Do What Consumers Say Matter? The Misalignment of Preferences with Unconstrained Ethical Intentions. Journal of Business Ethics, 76, 361-383.

Bagozzi, R. (2000). The Poverty of Economic Explanations of Consumption and an Action Theory Alternative. Managerial and decision economics, 21, 95-109.

Barnett, C., Cafaro, P., \& Newholm, T. (2005). Philosophy and Ethical Consumption. In R. Harrison, T. Newholm \& D. Shaw (Eds.), The Ethical Consumer. London: Sage Publications Ltd.

Belk, R. (1975). Situational Variables and Consumer Behavior. Journal of Consumer Research, 2, 157-164. 
Belk, R., Devinney, T. M., \& Eckhardt, G. (2005). Consumer Ethics Across Cultures. Consumption, Markets and Culture, 8(3), 275-289.

Brown, M., Pope, N., \& Voges, K. (2003). Buying or Browsing?: An Exploration of Shopping Orientations and Online Purchase Intention. European Journal of Marketing, 37(11/12), 1666-1684.

Brunk, K. H. (2010). Exploring origins of ethical company/brand perceptions - A consumer perspective of corporate ethics. Journal of Business Research, 63(3), 255-262.

Carrigan, M., \& Attalla, A. (2001). The myth of the ethical consumer - do ethics matter in purchase behavior? Journal of Consumer Marketing, 18(7), 560-577.

Carrington, M. J., Neville, B. A., \& Whitwell, G. J. (2010). Why Ethical Consumers Don't Walk Their Talk: Towards a Framework for Understanding the Gap Between the Ethical Purchase Intentions and Actual Buying Behavior of Ethically Minded Consumers. Journal of Business Ethics, 97, 139-158.

Chatzidakis, A., Hibbert, S., \& Smith, A. P. (2007). Why People Don't Take their Concerns about Fair Trade to the Supermarket: The Role of Neutralization. Journal of Business Ethics, 74, 89-100.

Cherrier, H. (2005). Using Existential-Phenomenological Interviewing to Explore Meanings of Consumption. In R. Harrison, T. Newholm \& D. Shaw (Eds.), The Ethical Consumer. London: Sage Publications Ltd.

Corbin, J., \& Strauss, A. (2008). Basics of Qualitative Research. Thousand Oaks, California: SAGE Publications.

Cooperative Bank. (2009). Ethical Consumerism Report 2009: Cooperative Bank UK. Crane, A., \& Matten, D. (2004). Business Ethics: A European Perspective. Oxford: Oxford University Press. 
De Pelsmacker, P., Driesen, L., \& Rayp, G. (2005). Do Consumers Care about Ethics? Willingness to Pay for Fair-Trade Coffee. The Journal of Consumer Affairs, 39(2), 363-385.

De Pelsmacker, P., \& Janssens, W. (2007). A Model for Fair Trade Buying Behavior: The Role of Perceived Quantity and Quality of Information and Product-specific Attitudes. Journal of Business Ethics, 75, 361-380.

Deshpande, R. (1983). Paradigms Lost: On Theory and Method in Research in Marketing. Journal of Marketing, 47, 101-110.

Dholakia, U. M., Bagozzi, R., \& Gopinath, M. (2007). How Formulating Implementation Plans and Remembering Past Actions Facilitate the Enactment of Effortful Decisions. Journal of Behavioral Decision Making, 20, 343-364.

Edmondson, A. C., \& McManus, S. E. (2007). Methodological Fit in Management Field Research. Academy of Management Review, 32(4), 1155-1179.

Elgin, D., \& Mitchell, A. (1977). Voluntary Simplicity: Lifestyle of the Future? The Futurist, $11,200-261$.

Elliot, R., \& Jankel-Elliot, N. (2003). Using Ethnography in Strategic Consumer Research. Qualitative Market Research: An International Journal, 6(4), 215-223.

Fisk, G. (1998). Green Marketing: Multiplier for Appropriate Technology Transfer? Journal of Marketing Management, 14(6), 657-676.

Freestone, O., \& McGoldrick, P. (2008). Motivations of the Ethical Consumer. Journal of Business Ethics, 79, 445-467.

Fukukawa, K. (2003). A Theoretical Review of Business and Consumer Ethics Research: Normative and Descriptive Approaches. The Marketing Review, 3, 381-401. 
Futerra Sustainability Communications Ltd. (2005). The Rules of the Game: The Principals of Climate Change Communication. London, UK: Department for Environment, Food and Rural Affairs.

Glasser, B., \& Strauss, A. (1967). The Discovery of Grounded Theory. Chicago: Aldine Publishing Co.

Gollwitzer, P. M. (1999). Implementation Intentions: Strong Effects of Simple Plans. American Psychologist, 54(7), 493-503.

Gollwitzer, P. M., \& Sheeran, P. (2006). Implementation intentions and goal achievement: a meta-analysis of effects and processes. Advances in experimental social psychology, $38,69-119$.

Goulding, C. (1999). Consumer research, interpretive paradigms and methodological ambiguities. European Journal of Marketing, 33(9), 859-873.

Goulding, C. (2005). Grounded Theory, ethnography and phenomenology: A comparative analysis of three qualitative strategies for marketing research. European Journal of Marketing 39(3/4), 294-308.

Hammersley, M., \& Atkinson, P. (2008). Ethnography - Principals in Practice (Third ed.). London: Routledge.

Harrison, R., Newholm, T., \& Shaw, D. (2005). Introduction. In R. Harrison, T. Newholm \& D. Shaw (Eds.), The Ethical Consumer. London: Sage Publications Ltd.

Holland, R., Aarts, H., \& Langendam, D. (2006). Breaking and creating habits on the working floor: A field-experiment on the power of implementation intentions. Journal of Experimental Social Psychology, 42(6), 776-783.

Kleine, R. E., \& Kleine, S. S. (2000). Consumption and Self-Schema Changes Throughout the Identity Project Life Cycle. Advances in Consumer Research, 27, 279-285. 
Lazzarini, S. G., \& de Mello, P. C. (2001). Government versus Self-regulation of Derivative Markets. Journal of Economics and Business, 53, 185-207.

Lincoln, Y. A., \& Guba, E. G. (1985). Naturalistic Inquiry. Beverly Hills: Sage.

Marcus, G. (1995). Ethnography in/of the world system: The emergence of Multi-Sited Ethnography. Annual Review of Anthropology, 24, 95-117.

McGrath, J. E. (1994). Methodology Matters: Doing Research in the Behavioral and Social Sciences (2nd ed.). San Francisco, CA: Morgan Kaufmann.

Miles, M., \& Huberman, A. (1994). Qualitative Data Analysis: A Sourcebook of New Methods. Newbury Park, CA: Sage.

Morwitz, V. G., Johnson, E., \& Schmittlein, D. (1993). Does Measuring Intent Change Behavior. Journal of Consumer Research, 20, 46-61.

Papies, E. K., Aarts, H., \& de Vries, N. K. (2009). Planning is for doing: Implementation intentions go beyond the mere creations of goal-directed associations. Journal of Experimental Social Psychology, 45(5), 1148-1151.

Polonsky, M. J. (1995). A stakeholder theory approach to designing environmental marketing strategy. The Journal of Business and Industrial Marketing, 10(3), 29-46.

Shaw, D., \& Clarke, I. (1999). Belief formation in ethical consumer groups: an exploratory study. Marketing Intelligence and Planning, 17(2), 109-119.

Shaw, D., Hogg, G., Wilson, E., Shui, E., \& Hassan, L. (2006). Fashion victim: the impact of fair trade concerns on clothing choice. Journal of Strategic Marketing, 14, 427-440.

Shaw, D., Newholm, T., \& Dickinson, R. (2006). Consumption as voting: an exploration of consumer empowerment. European Journal of Marketing, 40(9), 1049-1067.

Shaw, D., Shiu, E., Hassan, L., Bekin, C., \& Hogg, G. (2007). Intending To Be Ethical: An Examination of Consumer Choice in Sweatshop Avoidance. Advances in Consumer Research, 34, 31-38. 
Shaw, D., \& Shui, E. (2002). An assessment of ethical obligation and self-identity in ethical consumer decision-making: a structural equation modeling approach. International Journal of Consumer Studies, 26(4), 286-293.

Sheeran, P., Trafimow, D., \& Armitage, C. J. (2003). Predicting behavior from perceived behavioral control: Tests of the accuracy assumption of the theory of planned behavior. British Journal of Social Psychology, 42, 393-410.

Spiggle, S. (1994). Analysis and Interpretations of Qualitative Data in Consumer Research. Journal of Consumer Research, 21, 491-503.

Spradley, J. (1979). The Ethnographic Interview. Orlando, Florida: Harcourt Brace Jovanovich

Szmigin, I., Carrigan, M., \& McEachern, M. G. (2009). The conscious consumer: taking a flexible approach to ethical behavior. International Journal of Consumer Studies, 33, 224-231.

Tybout, A. M., \& Yalch, R. F. (1980). The Effect of Experience: A Matter of Salience? Journal of Consumer Research, 6(4), 406-413.

Vermeir, I., \& Verbeke, W. (2008). Sustainable food consumption among young adults in Belgium: Theory of Planned Behavior and the role of confidence and values. Ecological Economics, 64, 542-553.

Verplanken, B. (2006). Beyond frequency: Habit as a mental construct. British Journal of Social Psychology, 45, 639-656.

Vinson, D. E., Scott, J. E., \& Lamont, L. M. (1977). The Role of Personal Values in Marketing and Consumer Behavior. Journal of Marketing, 41(2), 44-50.

Wallendorf, M., \& Belk, R. W. (1989). Assessing Trustworthiness in Naturalistic Consumer Research. In E. C. Hirschman (Ed.), Interpretive Consumer Research (pp. 69-84). Provo, UT: Association for Consumer Research. 
Webb, T., Sheeran, P., \& Luszczynska, A. (2009). Planning to break unwanted habits: Habit strength moderates implementation intention effects on behavior change. British Journal of Social Psychology, 48, 507-523.

Young, M. R., DeSarbo, W. S., \& Morwitz, V. G. (1998). The Stochastic Modeling of Purchase Intentions and Behavior. Management Science, 44(2), 188-202. 
Table 1

Informant Characteristics

\begin{tabular}{|c|c|c|c|}
\hline Pseudonym & Generation & Occupation & Partner / Family \\
\hline David & Gen X & $\begin{array}{l}\text { (a) Local Government - waste collection program } \\
\text { (P/T). } \\
\text { (b) Coordinates an ethical consumer network }\end{array}$ & Partner, 2 children \\
\hline Brigit & Gen X & $\begin{array}{l}\text { (a) Local Government -sustainability }(\mathrm{F} / \mathrm{T}) \\
\text { (b) Coordinates an environmental awareness group } \\
\text { (volunteer) }\end{array}$ & Partner \\
\hline Helen & Gen Y & NGO - sustainability $(\mathrm{F} / \mathrm{T})$ & Single \\
\hline Sally & Gen X & Educator (Higher Ed.) - Sustainability (F/T) & Partner, 1 child \\
\hline Beth & Gen X & Undisclosed & Partner \\
\hline Rachel & Baby Boomer & $\begin{array}{l}\text { (a) Educator (retired) } \\
\text { (b) Coordinates a local community cooperative } \\
\text { agriculture group (volunteer) }\end{array}$ & $\begin{array}{l}\text { Partner, grown-up } \\
\text { children }\end{array}$ \\
\hline Claire & Baby Boomer & Consultant $(\mathrm{F} / \mathrm{T})$ & $\begin{array}{l}\text { Partner, grown-up } \\
\text { children }\end{array}$ \\
\hline Peter & Gen X & Government - Sustainability (F/T) & Single \\
\hline Camille & Gen X & Researcher $(\mathrm{F} / \mathrm{T})$ & Partner, 1 child \\
\hline Anita & Gen $X$ & Dietician (P/T) & Single \\
\hline Megan & Gen Y & Government - Sustainability $(\mathrm{F} / \mathrm{T})$ & Partner \\
\hline Tom & Gen Y & Accountant $(\mathrm{F} / \mathrm{T})$ & Partner \\
\hline Rosa & Gen Y & Government - Finance (F/T) & Single \\
\hline
\end{tabular}


Table 2

Informant Research Participation

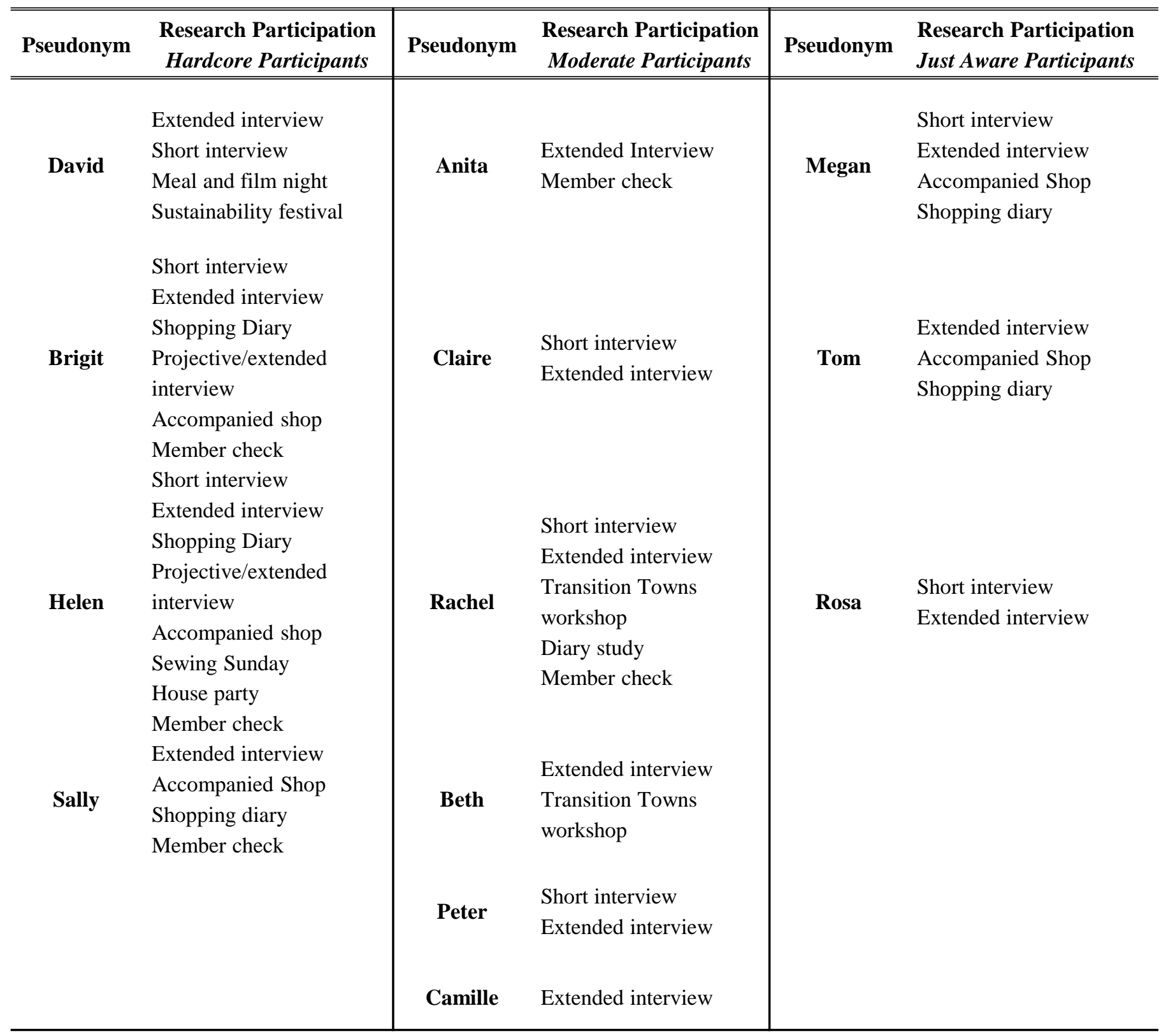


Table 3

Data Summary

\begin{tabular}{ll}
\hline \hline Activity/Data Format & Details/Volume \\
\hline \hline Duration of Study & Nine Months \\
Transcribed Material & 445 pages \\
Photographic Material & 34 images \\
Video Footage & 63 minutes \\
Field Notes & 49 pages \\
Coded Observations & First data set: 1728 \\
\hline
\end{tabular}


Table 4

Informant profiles

\begin{tabular}{|c|c|}
\hline $\begin{array}{c}\text { Informant } \\
\text { Profile }\end{array}$ & Distinguishing Features \\
\hline Hard-core (HC) & $\begin{array}{l}\text { - Multiple primary ethical concerns integrated into daily choices and identity } \\
\text {-Each primary ethical concern is researched and advocated } \\
\text { - Rarely find products that meet all of their primary ethical concerns, and are } \\
\text { constantly having to 'trade-off' between these concerns } \\
\text { - Also have secondary ethical concerns, which are still important, but of lower } \\
\text { priority and awareness }\end{array}$ \\
\hline Moderate (Mod) & $\begin{array}{l}\text { - Single primary ethical concern integrated into daily choices and identity } \\
\text { - Single primary ethical concern researched and advocated } \\
\text { - Also have secondary ethical concerns, which are still important, but of lower } \\
\text { priority and awareness }\end{array}$ \\
\hline $\begin{array}{l}\text { Just Aware (JA) and } \\
\text { Not Aware (NA) }\end{array}$ & $\begin{array}{l}\text {-Single primary ethical concern and possibly secondary ethical concerns. } \\
\text { - Basic awareness of the primary concern, but yet to engage in in-depth research } \\
\text { - Yet to form a connection between their ethical concern and their consumption at all } \\
\text { (NA), or yet to integrate their ethical concern into their consumption decisions on an } \\
\text { ongoing basis (JA). }\end{array}$ \\
\hline
\end{tabular}




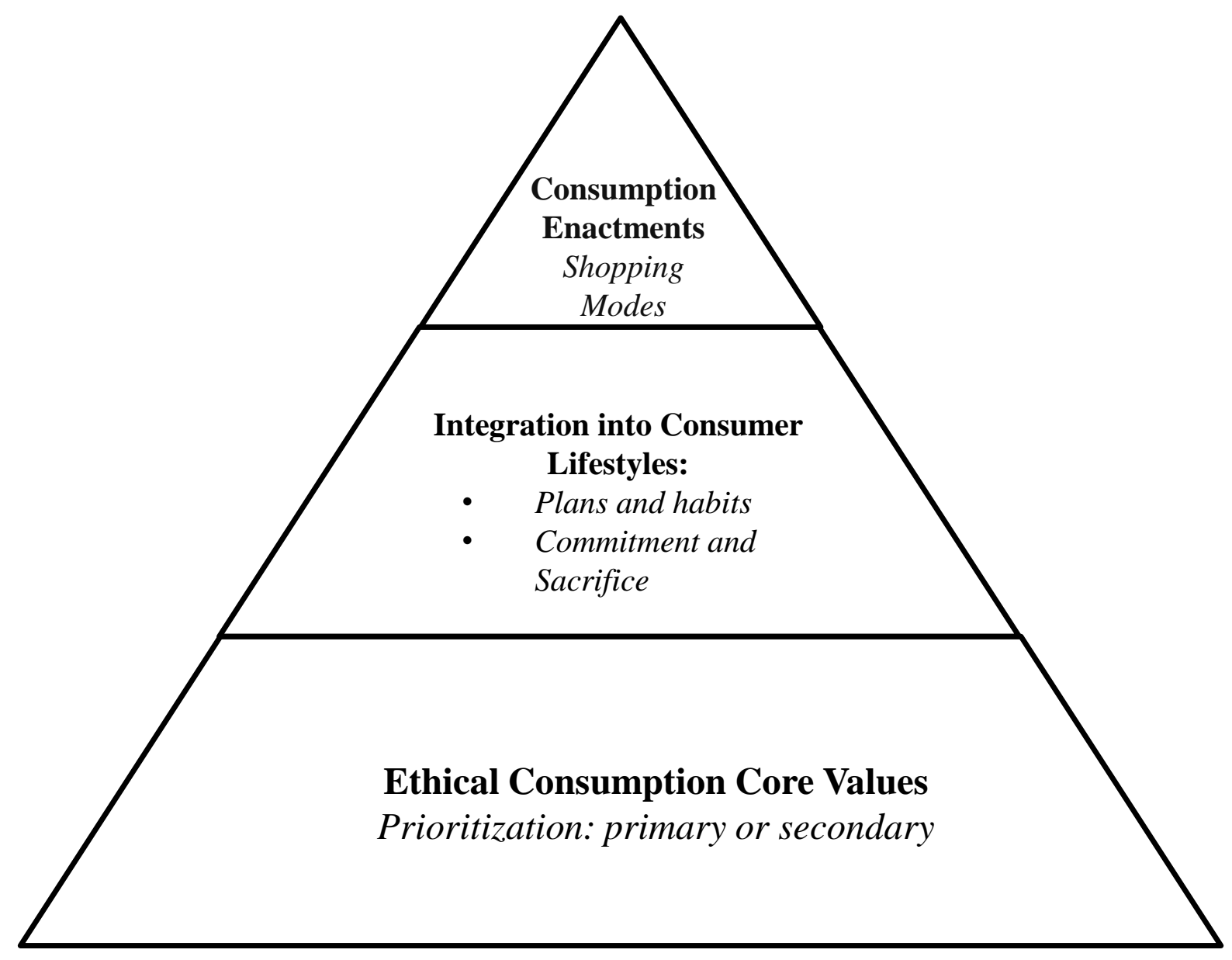

Figure 1

Core Motivational Hierarchy 


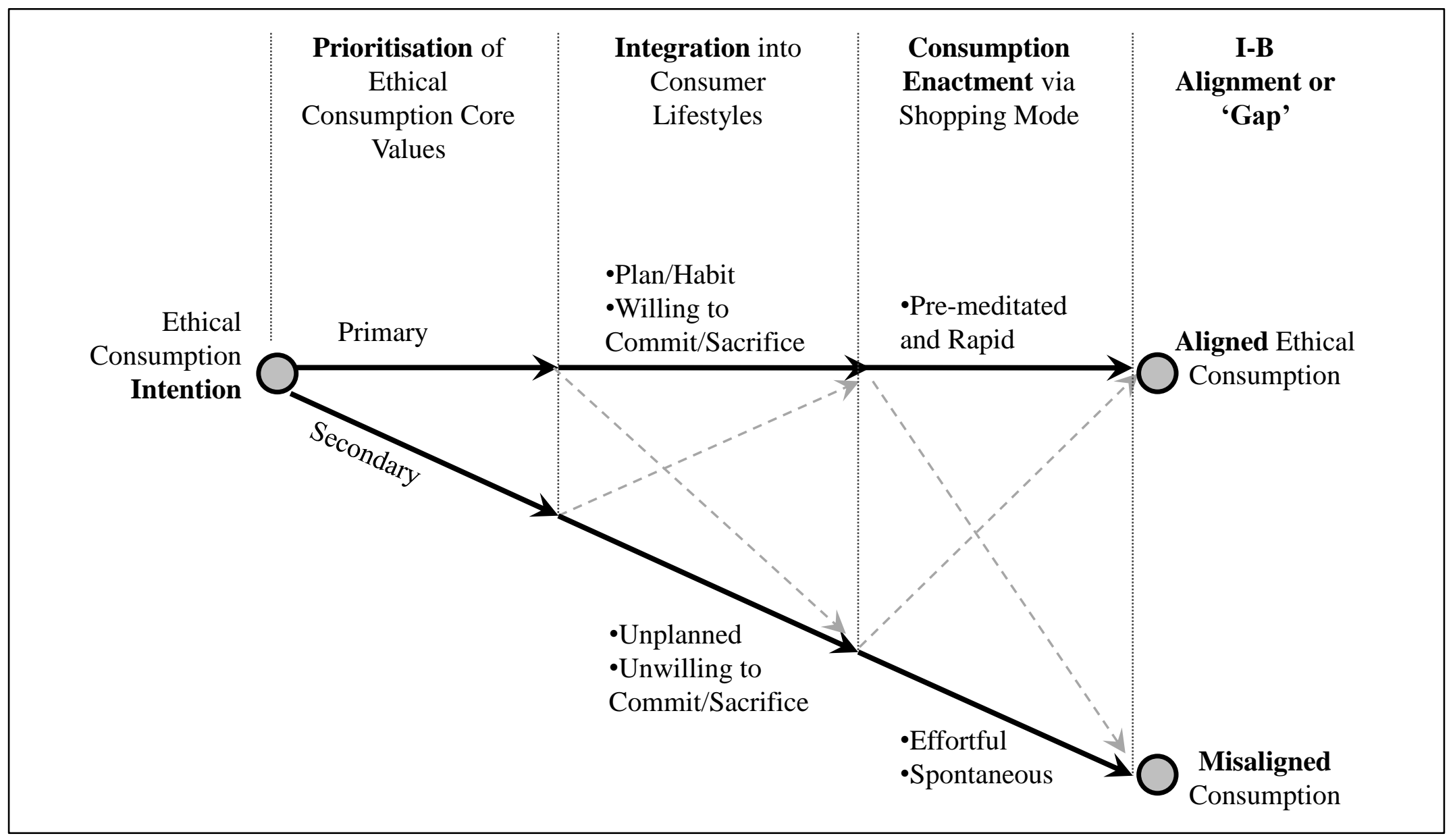

Figure 2

The Translation of Ethical Consumption Intentions into Actual Behavior 


\section{University Library}

\section{- $\mathrm{M}$ IIN E R VA A gateway to Melbourne's research publications}

Minerva Access is the Institutional Repository of The University of Melbourne

Author/s:

Carrington, MJ;Neville, BA;Whitwell, GJ

Title:

Lost in translation: Exploring the ethical consumer intention-behavior gap

Date:

2014

Citation:

Carrington, M. J., Neville, B. A. \& Whitwell, G. J. (2014). Lost in translation: Exploring the ethical consumer intention-behavior gap. Journal of Business Research, 67 (1), pp.2759-2767. https://doi.org/10.1016/j.jbusres.2012.09.022.

Persistent Link:

http://hdl.handle.net/11343/247863 